\title{
Editorial: Research excellence: citing, being cited and the $\mathrm{H}$ index
}

Elisabete A. Silva PhD, FRICS, RTPI

Senior Lecturer, Department of Land Economy, University of Cambridge, UK

During the past few years a lot has been stated about productivity in research and the metrics to evaluate such productivity. Depending on the subject being discussed, many people in academia will state that the concept of metric in itself is wrong and research excellence shouldn't be viewed as resulting from metric(s), from a measurement; that by measuring we narrow down everything to a value and therefore leave outside a lot of other things helpful to understand research excellence.

Nevertheless, pragmatism is required when fast amounts of funding are available and the impacts of research move entire economies, generate money, employment, patents, industrial production, that save lives and make the world move and progress. As a consequence, countries, universities, departments and researchers are ranked accordingly to a set of metrics. This has become increasingly important in the last decade in the sciences and engineering and is now becoming the norm in the social sciences and humanities.

One such metric is the $\mathrm{H}$ index. In the past, the pure action of citing a work would be a direct action of acknowledging that specific work was used in order to expand our own research. Nowadays, while this is still at the core of every paper/book/ report, citations are used as a measure of excellence, besides the content of the paper itself. The pure fact that one cites a paper/book has a direct implication, not only on our own paper, but also on the other person's publication - we will increase his/her number of citations for that particular paper. Therefore, while the act of citing is still important, the act of being cited became equally important.

Not only is the number of papers per researcher important, but also the number of citations each specific paper had until the present moment. And this relationship between number of papers and citations will indicate the level of success of a researcher/author. The $\mathrm{H}$ index is the metric that demonstrates that relationship. In the science and engineering subjects, projects are won/lost, prizes are awarded, and promotions will be granted depending on the $\mathrm{H}$ factor of a researcher. While in the sciences and engineering, the closer you are to applied fields, the higher the citation numbers, the average will point to a $\mathrm{H}$ index value of approximately 15-25 for full professors. In the social sciences and humanities, a $\mathrm{H}$ index of around 5-10 tends to grant a full professorial promotion. The London School of Economics (London, UK) found that (full) professors in the social sciences had average $\mathrm{H}$ indices ranging from $2 \cdot 2$ (in law) to $7 \cdot 6$ (in economics). On average across the disciplines, a full professor in the social sciences had a $\mathrm{H}$ index of $4 \cdot 9$, whereas a senior lecturer (associate professor) had a $\mathrm{H}$ index of $2 \cdot 2$ (London School of Economics, 2015).

Suddenly promoting research became a must, not only because of the content in itself but also because of the awareness factor. Being aware of what is being published and making others aware of your own work is the key to success; as a consequence, we have search engines dedicated to this (e.g. WoK, Scopus and Google Scholar).

It is interesting to remember how, when I was a student, some of my academic mentors kept mentioning 'don't forget that unpublished work is not work' and, as a consequence of such statements, some of us would make that effort, going beyond the mere preparation of the manuscript and getting a diploma. For those not going beyond the ultimate goal of submitting the manuscript of the $\mathrm{PhD}$ dissertation, there was always that final comment before the graduation ceremony: 'all that work just to shelve the dissertation in a dusty corner of the library'.

Why is this important to UDP, to its authors and its papers? In an era of awareness, making others aware of the work is as important as to develop the paper itself ... otherwise how can we move towards more socioeconomic and environmental progress? How can we make sure others build on our research and progress?

Nevertheless, and while I consider that metrics are important and there should be criteria to evaluate progress, at the end of the day a paper is always a paper. A research paper needs to demonstrate innovation and produce the linking points between its work and the work it builds on, as a consequence innovation and citations are still one of the most important 
elements in a paper, a good paper will be innovative and at the same time will demonstrate how it built innovation by citing work, how it moved forward from existent research. And if a good paper does that, it will be able to produce many 'times cited' - as a consequence that paper and those citations will end up contributing to the authors and other cited papers authors' success. It is interesting to see that a $\mathrm{H}$ index can indirectly reveal so much about being fair and acknowledge other people's work through citation, and by doing so increase our own productivity and excellence.

Urban Design and Planning (UDP) strives to achieve the same goals; a research paper needs to be innovative and demonstrate progress, the context needs to bridge with existing research, with methods and/or with the past researchers. By doing so, UDP innovates, and assures the ethical and transparent delivery of information that acknowledges those that are or were involved in the production of research being addressed. This issue of UDP emphasises this need once more, presenting three innovative research papers: 'Security sensitivity index: evaluating urban vulnerability' by Shach-Pinsly and Ganor (2015); 'A framework for analysing neighbourhood resilience' by Uda and Kennedy (2015); and 'Strategic redevelopment of brownfield sites in Tehran, Iran' by Zekavat and Motamedi (2015).
What do these papers have in common? Their different approaches, their answers to different questions, their use of different methods and case studies, these three papers organised the research accordingly to an outline of the problem and research context, producing a clear description of methodology and results and all used citation as a clear mark of research excellence.

\section{REFERENCES}

London School of Economics (2015) http://blogs.lse.ac.uk/ impactofsocialsciences/the-handbook/chapter-3-keymeasures-of-academic-influence/ (accessed 28/04/2015).

Shach-Pinsly D and Ganor T (2015) Security sensitivity index: evaluating urban vulnerability. Proceedings of the Institution of Civil Engineers - Urban Design and Planning 168(3): 115-128, http://dx.doi.org/10.1680/udap.13.00015. Uda M and Kennedy C (2015) A framework for analysing neighbourhood resilience. Proceedings of the Institution of Civil Engineers - Urban Design and Planning 168(3): 129-145, http://dx.doi.org/10.1680/udap.14.00028.

Zekavat K and Motamedi R (2015) Strategic redevelopment of brownfield sites in Tehran, Iran. Proceedings of the Institution of Civil Engineers - Urban Design and Planning 168(3): 146-156, http://dx.doi.org/10.1680/udap.14.00036. 